\title{
A novel sensitivity analysis on friction spot joining process performed on aluminum/polycarbonate sheets by simulation
}

\author{
Giuseppe Serratore ${ }^{1} \cdot$ Francesco Gagliardi $^{1}$ - Clara Argerich Martín ${ }^{2} \cdot$ Ruben Ibanez Pinilo $^{2}$ - Elias Cueto ${ }^{3}$. \\ Luigino Filice $^{1} \cdot$ Francisco Chinesta $^{4}$
}

Received: 22 April 2020 / Accepted: 7 July 2020

(C) The Author(s) 2020

\begin{abstract}
The manufacturing research has been focusing on the improvement of product performance and lightweight design. The synergic effects between material properties and manufacturing solutions have been considered, extensively. Specifically, joining techniques have been developing with the aim to propose new suitable solutions considering dissimilarities in the properties of the materials that have to be combined. Setting of new manufacturing routes is, therefore, a demanding task. In this direction, there are several methods available in the scientific literature that are focused on sensitivity analysis or optimization/minimization techniques to reduce the necessary attempts or to find a solution/correlation among big data. In this work, the goal of obtaining high joint efficiency between Aluminum and Polycarbonate sheets by the Friction Spot Joining process is considered as a case study. This process must face two main issues, i.e., the mechanical, physical and chemical compatibilities between the parts and the integrity protection of the polymeric sheet near the joining area. The process parameters influences were analysed using numerical simulations performed by a commercial FE code. The number of executed analyses was reduced with a planned DoE. From these results, the Code2Vect algorithm was employed with the aim to visualize, efficiently, high-dimensional data and to evaluate the influences of some identified parameters on the process answer. Finally, a transfer function involving the input and output quantities of interest was derived in a compact representation by a Newton Raphson minimization technique.
\end{abstract}

Keywords Mechanical fastening $\cdot$ Dissimilar materials $\cdot$ Friction spot joining $\cdot$ Machine learning $\cdot$ Code2Vect $\cdot$ Newton-Raphson

\section{Introduction}

As continuously demanded by aerospace and automotive industries, academic and industrial research have been focusing on the development of lightweight components for pursuing both $\mathrm{CO}_{2}$ reduction and performant solutions through the combination of different lightweight materials such as Aluminum, Magnesium alloys and thermoplastic materials. In this context, the main goal is the development of peculiar techniques suitable to joint these materials through the optimization of advanced and sustainable connections.

Francisco Chinesta

francisco.CHINESTA@ensam.eu

1 Italy

2 PIMM, Arts et Métiers Institute of Technology, CNRS, CNAM, HESAM University, 151, boule-vard de l'Hôpital, 75013 Paris, France

3 Aragon Institute of Engineering Research, Universidad de Zaragoza, Maria de Luna, s.n, 50018 Zaragoza, Spain

$4 \quad$ PIMM Lab \& ESI Group chair, Arts et Métiers ParisTech 151 Boulevard de l'Hôpital, F-75013 Paris, France 


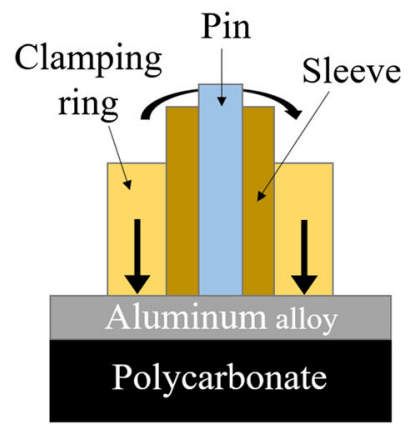

a)

b)

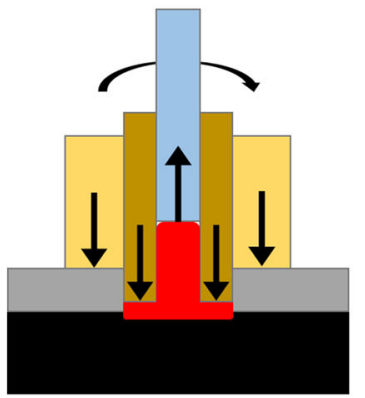

c)

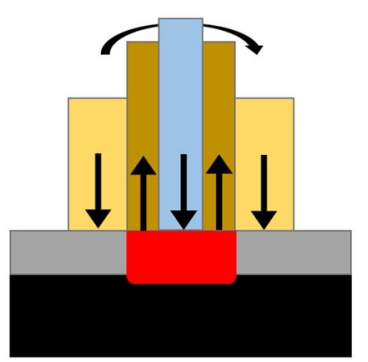

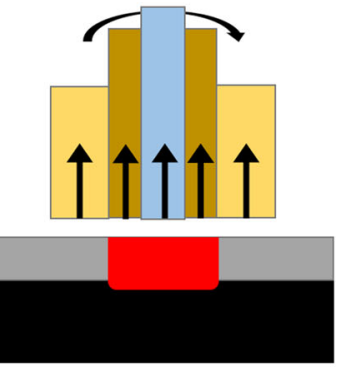

Fig. 1 Schematic illustration of the Friction Spot Joining Process. The Sleeve plunging softens the Aluminum alloy (a); spot refilling (b) and joint consolidation (c)

The main obstacle lies in the dissimilar properties of the materials that need to be connected, which affect the process parameters to be employed. For example, when an Aluminum alloy is joined with a thermoplastic material, two main problems can arise, i.e., the mechanical, physical and chemical compatibilities between the parts and the preservation of the polymeric sheet nearby the joining area. To face these issues, the effects of the process parameters on the joint quality need to be understood by means of numerical and experimental tests and data analysis.

New mechanical fastening methods have been proposed as joining processes to manufacture dissimilar parts [1, 2]. Among these, friction stir based techniques have been developed in different variants [3, 4]. Friction Spot Joining (FSpJ) represents a promising solid-phase joining solution. This technique was patented by Helmholtz-Zentrum Geesthacht [5] for producing thin-sheet metal-polymer joints and was derived from the friction spot welding technology [6, 7]. The spot joint is performed with the aid of a non-consumable tool. As depicted in Fig. 1, the tool is composed of two movable parts,
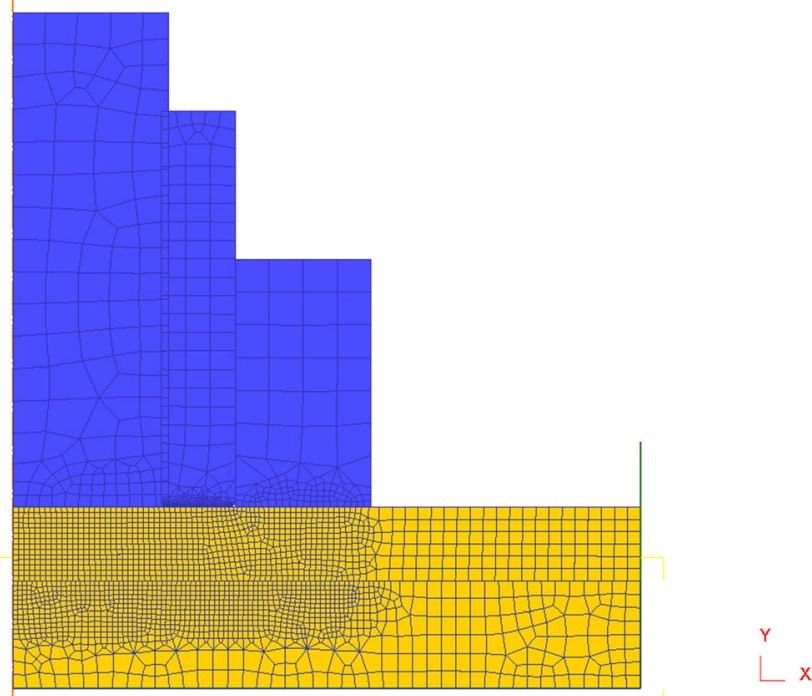

Fig. 2 2D Axisymmetric finite element model for the FSpJ process simulation pin and sleeve, which are coaxial to a clamping ring. This last rigid tool ensures a continuous contact between the parts to be joined. Both pin and sleeve are characterized by a rotational speed, which allows heating the joined area.

Moreover, the produced heat depends on the plunge depth of the pin inside the metallic sheet and on the joining time, too. A schematic illustration of the whole FSpJ process is provided in Fig. 1a, b, and c.

In this process, the complex dynamics, such as a material stirring, high deformation, heat flow, combination of material with different thermal and material flow properties, etc., should be considered. Several studies in the literature deal with experimental and numerical analysis [8, 9]. Most of the numerical models available in literature for the FSpJ simulation were derived from the friction spot welding process [10-14]. In each proposed numerical research, the main problem is the mesh distortion owing to the stirring effect of the tool rotation. On the other hand, this phenomenon is computationally expensive to solve and can result in simulation failures.

The research herein proposed focused on a 2D axisymmetric numerical model suitable for the evaluation of specific process outputs, which have an impact on the performance of the achieved connections. According to a planned Design of Experiments (DoE), 30 numerical tests, set by a commercial FE code, were performed. As explained in the following section, the Code2Vect [15] algorithm was employed on these results with the purpose to visualize high-dimensional data and to evaluate: a) the influences of the identified process parameters and b) the process responses at their variation. Finally, for each identified parameters a compact representation involving the input and output quantities of interest was derived using a NewtonRaphson minimization technique [16].

Table 1 Johnson-Cook plasticity model constant for AA 1050 [20] and AA 2024 [21]

\begin{tabular}{llllllll} 
Material & $\mathrm{A}[\mathrm{MPa}]$ & $\mathrm{B}[\mathrm{MPa}]$ & $\mathrm{C}$ & $\mathrm{n}$ & $\mathrm{m}^{\mathrm{T}}$ & $\mathrm{T}_{\text {room }}\left[{ }^{\circ} \mathrm{C}\right]$ & $\mathrm{T}_{\text {melt }}\left[{ }^{\circ} \mathrm{C}\right]$ \\
\hline AA 1050 & 110 & 150 & 0.01 & 0.4 & 1 & 20 & 640 \\
AA 2024 & 352 & 440 & 0.0083 & 0.42 & 1 & 20 & 645 \\
\hline
\end{tabular}


Table 2 Material coefficients for polycarbonate [22]

\begin{tabular}{lllllllll} 
Material & $\mathrm{C} 1$ & $\mathrm{C} 2$ & $\mathrm{~m}$ & $\mathrm{a}(\mathrm{K})$ & $\mathrm{K}(\mathrm{MPa} \mathrm{sm})$ & $\mathrm{C} 3(\mathrm{sm})$ & $\mathrm{C} 4$ & $\alpha$ \\
\hline $\mathrm{PC}$ & 4.02 & 0.038 & 415 & 28.4 & 0.03 & 5.8 & 5.8 & 6.8
\end{tabular}

\section{Proposed approach}

This section summarises the proposed approach for the sensitivity analysis on FSpJ. Specifically, two aluminum alloys (AA), with different mechanical properties, were joined to a polycarbonate (PC) sheet, separately. In the next sections, the developed FE model, the planned DoE, the Code2Vect algorithm and the Newton-Raphson minimization technique are fully described.

\section{FEM model description}

The numerical tests were performed with a commercial finite element code, DEFORM 2D"M . Specifically, the "Torsion" mode in the geometry section was employed to simulate the heat generation by friction between the contact surfaces, without affecting the computational effort, excessively. The basic hypothesis of this approach is to neglect the material stirring around the tool, which could be simulated only by a 3D approach. Nevertheless this simplification, as proved in the results section, this $2 \mathrm{D}$ extended model resulted to be suitable for the FSpJ analysis.

More in the model details, the tools were assumed to be rigid while only the two plates were set as deformable. The AA and PC parts are, resperctivelly, $1.5 \mathrm{~mm}$ and $2.17 \mathrm{~mm}$ thick according to the ASTM D3528, which rules the double lap shear (DLS) tests. Regarding the tool, a diameter of $6 \mathrm{~mm}$ was considered for the Pin, a diameter of $9 \mathrm{~mm}$ for the Sleeve and a diameter of $14.5 \mathrm{~mm}$ for the Clamping ring [8].

Figure 2 shows the assumed 2D axisymmetric finite element model. All the setup was meshed with approximatively 2500 elements.

Between the two plates, a coulomb friction coefficient of 0.5 was set while a shear coefficient of 0.5 was considered between all the other surfaces [17]. Additionally, the heat transfer coefficient between the $\mathrm{AA}$ and the $\mathrm{PC}$ was set equal

Table 3 FSpJ process parameters and their respective levels (min, max, and step)

\begin{tabular}{llllll}
\hline Factors & Symbol & Unit & Min & Max & Step \\
\hline Rotational speed & RS & Rpm & 1000 & 3000 & 100 \\
Plunge depth & PD & mm & 0.5 & 1 & 0.1 \\
Joining time & JT & S & 4 & 8 & 0.5 \\
Material & AA & - & AA 1050 & AA 2024 & - \\
\hline
\end{tabular}

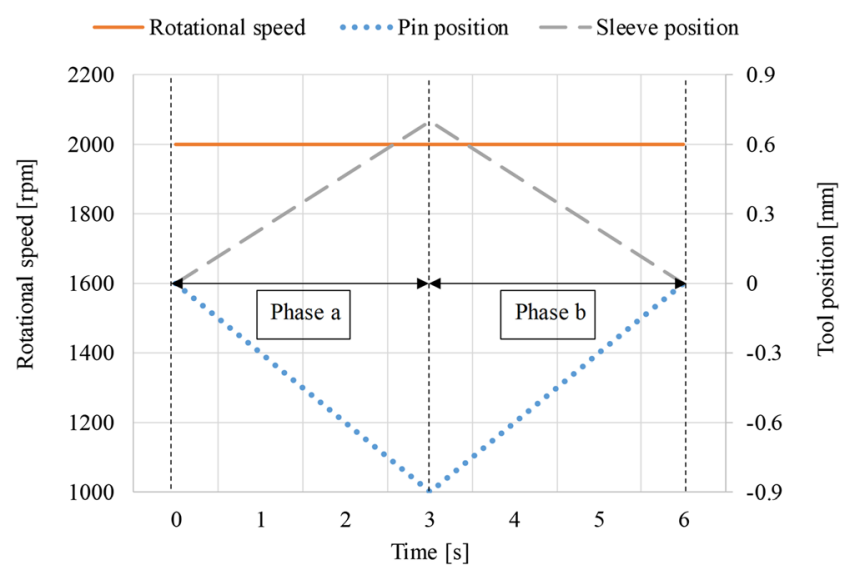

Fig. 3 Variation monitoring diagram of the phases "a" and "b" for the first joining condition

to $0.2 \mathrm{~N} /\left(\mathrm{m} \cdot \mathrm{s} \cdot{ }^{\circ} \mathrm{C}\right)$ [18]. The Johnson-Cook's model [19] was employed to set the constitutive AA models. Table 1 sums up the Johnson-Cook parameters for both materials, i.e. AA 1050 and AA 2024. The effects of strain hardening, thermal softening, and strain rate sensitivity are taken into account.

Concerning the PC part, the constitutive material model was expressed by the DSGZ [22], a viscoplastic phenomenological model developed for glassy or semi-crystalline polymers. With that model, the effect of the strain, strain rate, temperature, softening and hardening is considered. Table 2 reports the coefficients used in this work. Finally, both elastic and thermal properties were considered temperaturedependent.

\section{Performed numerical simulations according to a planned DoE}

The proposed methodology is generally applicable. This is able to operate both with reduced data and big data. However, since the sample of data came from numerical simulations, a DoE with Latin Hypercube (LH) sampling was set to reduce the number of simulations. In this way, we demonstrate the strength of the methodology, which can work with a reduced sample of data, following the so-called smart data paradigm. Table 3 summarizes the investigating four process parameters, i.e. rotational speed, plunge depth, joining time and type of aluminum alloy, upon which the DoE based on LH sampling, was applied. The pin depth, instead, was connected to the plunge depth and, for this reason, was not taken into account in the DoE and in the successive result discussion.

The resulting 30 joining conditions are listed in Appendix (Table 4). For the clearness of the paper, Fig. 3 shows the simulated phases for the first joining condition, following Fig.1a and Fig.1b. 
Fig. 4 Input space (a) and target vector space (b)

a)

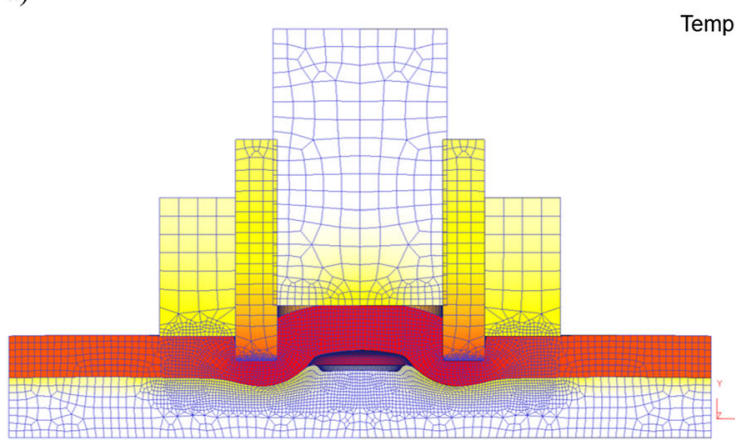

a) Representation Space

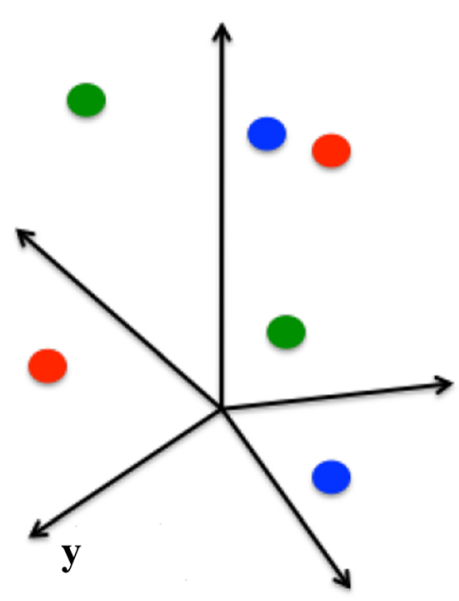

b) Vector Space

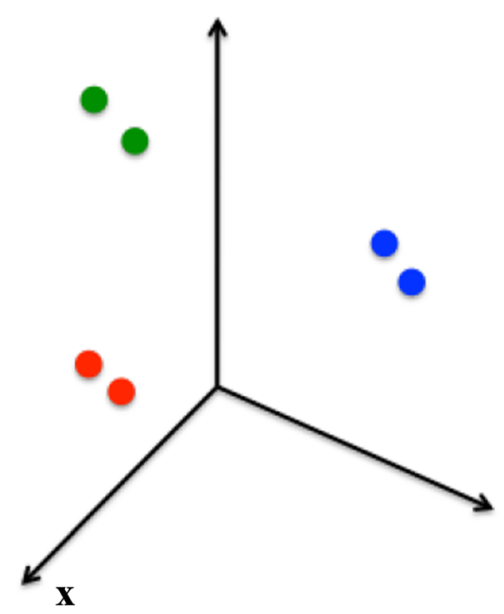

Fig. 5 Typical result for the FSjP process simulation, at the end of the phase "a" (a) and "b" (b)

Fig. 6 The selected results: the maximum temperature of the peak, the maximum temperature of the valley and the interlocking area

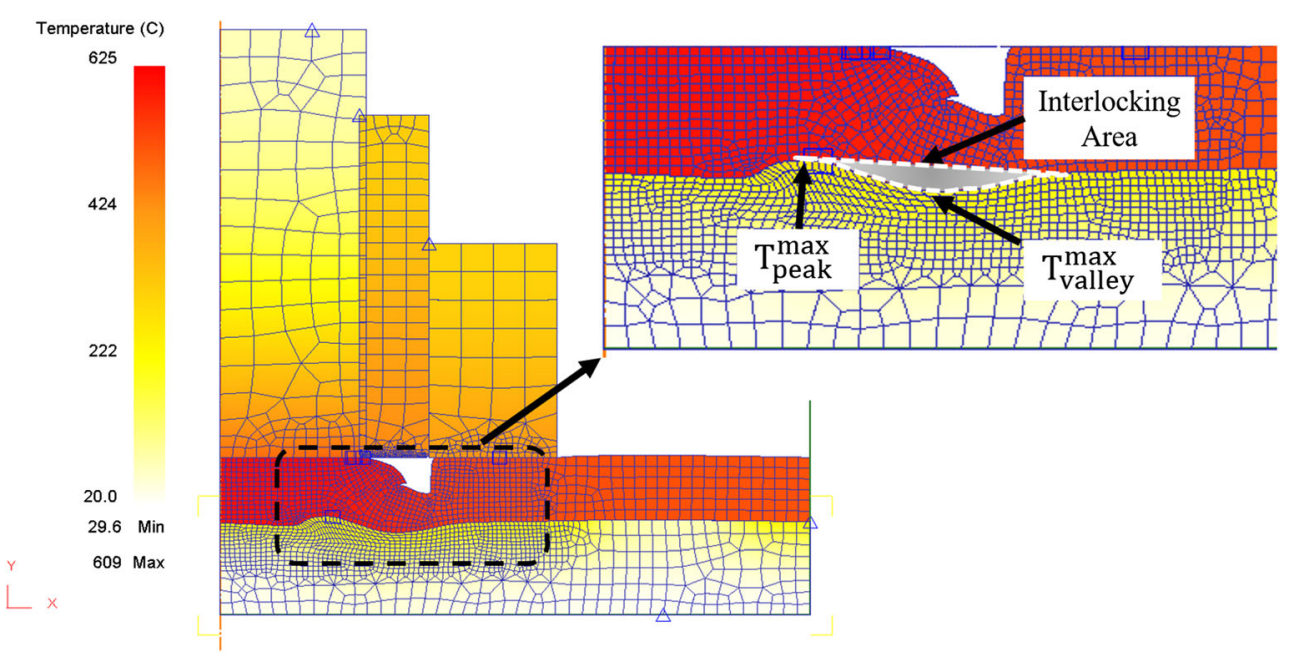


Table 5 Range of the results obtained by the FE simulations

\begin{tabular}{lllll}
\hline Factors & Symbol & Unit & Min & Max \\
\hline Maximum temperature of the peak & $M T P$ & ${ }^{\circ} \mathrm{C}$ & 169 & 335 \\
Maximum temperature of the valley & $\mathrm{MTV}$ & ${ }^{\circ} \mathrm{C}$ & 146 & 304 \\
Interlocking Area & IA & $\mathrm{mm}^{2}$ & 4.59 & 25.44
\end{tabular}

\section{Code2Vect}

In the Artificial intelligence framework, the most common techniques such as decision trees or neural networks [23] rely on "big-data" in order to build regression models. When scarce data are available, the use of such techniques is limited. Thus, Code2Vect was employed. Another motivation behind the adoption of Code2Vect resides on the aim to visualize high-dimensional data.

So, with this background, the algorithm was used to represent in a low-dimensional space high-dimensional heterogeneous data. This technique, sketched in Fig. 4, maps points from a complex representation space to a simple target space equipped of a Euclidean metric allowing the quantification of distances enabling the use of usual machine learning procedures [24].

We assume that the points in the origin space (input space) consist of arrays $\mathbf{y}$ composed on $\mathrm{D}$ entries. They are assumed arrays because they cannot be considered vectors, and are noted by $\mathbf{y}_{\mathbf{i}}$ in $\mathbf{R}^{\mathbf{D}}$. Their images in the vector space are noted

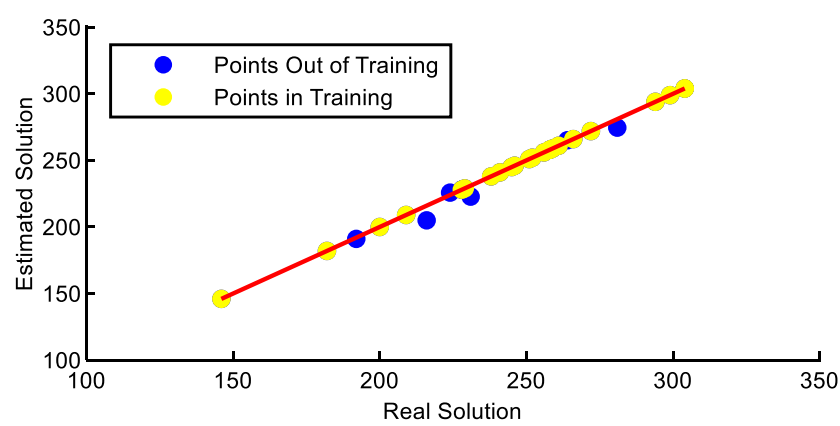

Fig. 8 MTV estimated solution

by $\mathbf{x}_{\mathbf{i}} \in \mathbf{R}^{\mathbf{d}}$, which have size of the reduced coordinates, this time real vectors subjected to the rules of coordinate transformation.

That vector space is equipped of the standard scalar product and the associated Euclidian distance. The mapping is described by the $\mathrm{d} \times \mathrm{D}$ matrix $\mathbf{W}$,

$\mathbf{x}=\mathbf{W y}$

where both, the components of $\mathbf{W}$ and the images $\mathbf{x}_{\mathbf{i}} \in \mathbf{R}^{\mathbf{d}}$, must be calculated. Each point $\mathbf{x}_{\mathbf{i}}$ keeps the label (value of the output of interest, herein assumed scalar) associated with the origin point $\mathbf{y}_{\mathbf{i}}$, denoted by $\mathbf{O}_{\mathbf{i}}$.

We would like placing points $\mathbf{x}_{\mathbf{i}}$, such that the Euclidian distance with each other point $\mathbf{x}_{\mathbf{j}}$ scales with their outputs difference, i.e.:
Fig. 7 MTV vector space representation
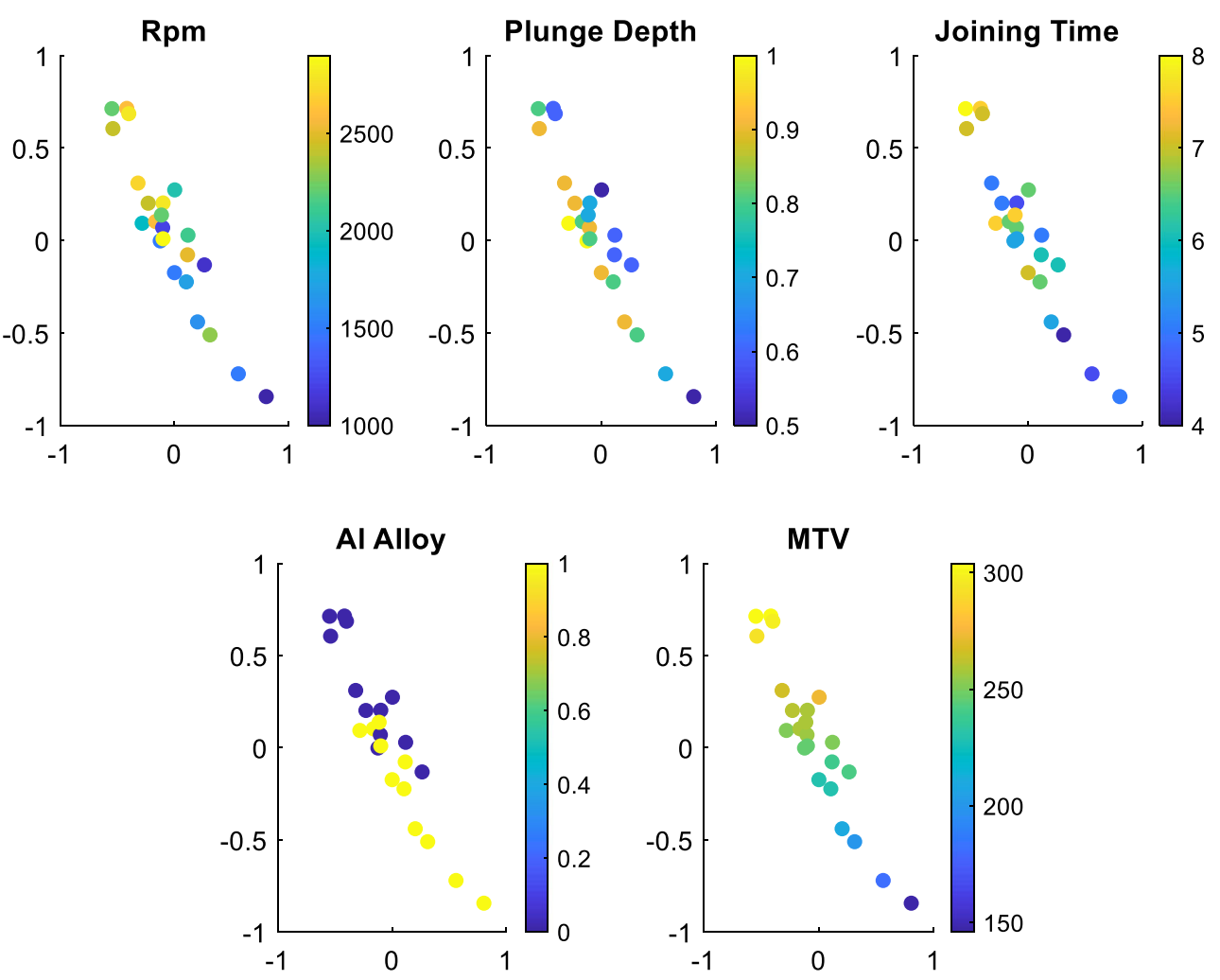
Fig. 9 MTP vector space representation

$$
\left(\mathbf{W}\left(\mathbf{y}_{\mathbf{i}}-\mathbf{y}_{\mathbf{j}}\right)\right) \cdot\left(\mathbf{W}\left(\mathbf{y}_{\mathbf{i}}-\mathbf{y}_{\mathbf{j}}\right)\right)=\left\|\mathbf{x}_{\mathbf{i}}-\mathbf{x}_{\mathbf{j}}\right\|^{\mathbf{2}}=\left|\mathbf{O}_{\mathbf{i}}-\mathbf{O}_{\mathbf{j}}\right|
$$

Linear mappings are limited and do not allow proceeding in nonlinear settings. Thus, a better choice consists of the nonlinear mapping $\mathbf{W}(\mathbf{y})$, expressible from the general polynomial form:

$\mathbf{W}(\mathbf{y})=\sum_{\mathrm{k}} \mathbf{W}_{\mathrm{k}} \mathrm{P}_{\mathrm{k}}(\mathbf{y})$

where $\mathbf{W}_{\mathbf{k}}$ and $\mathrm{P}_{\mathbf{k}}(\mathbf{y})$ are, respectively, matrices and a polynomial basis. The associated nonlinear problem can be efficiently solved by employing an adequate linearization strategy, e.g. the Newton-Raphson's method. The procedure followed is:

- Run Code2Vect for each one of the three quantities of interest;

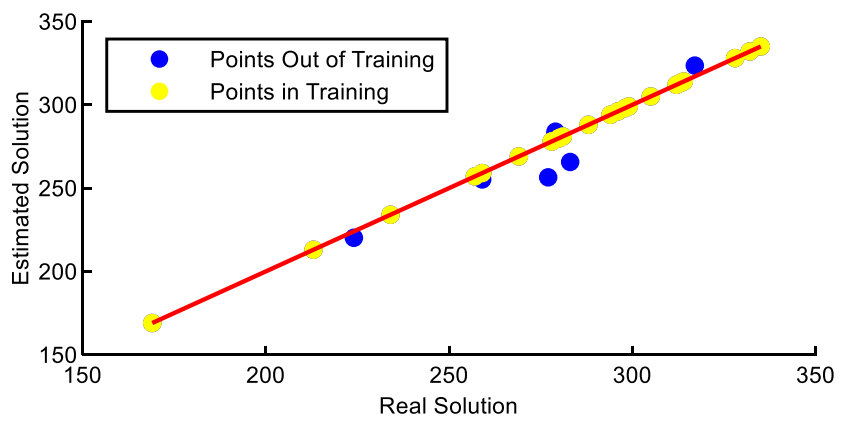

Fig. 10 MTP estimated solution
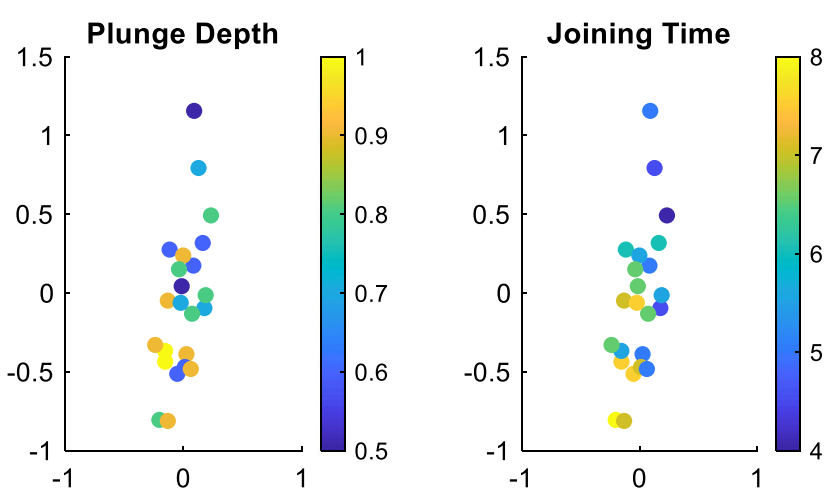

Al Alloy
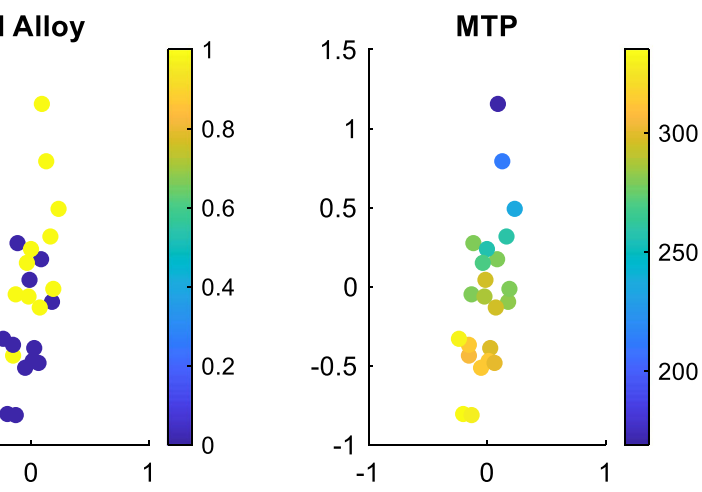

- Plot the vector space (reduced space) colored with each one of the inputs;

- $\quad$ Test the regression capabilities of Code2Vect using $80 \%$ of data as training data. For the regression, we use points not used in the training, we place them in the reduced space by means of $\mathbf{W}$ and, subsequently, we perform an interpolation of the value of the quantity of interest in the neighbor points.

\section{Extracting a closed model}

The objective of this work was also to find a compact representation of the data itself, that meaning, an empirical equation able to explains the behavior behind the data. For that purpose, a Newton-Raphson minimization technique was defined for each AA in a template as follows:

$\mathrm{QoI}=\mathrm{ctt} * \mathrm{RS}^{\mathrm{a}} * \mathrm{PD}^{\mathrm{b}} * \mathrm{JT}^{\mathrm{c}}$

where $Q o I$ stands for the quantity of interest.

\section{Results and discussion}

In this section, the results of the proposed approach are presented. In sequence, the next paragraphs show the FE simulations results, the application of the Code2Vect algorithm, 
Fig. 11 IA vector space representation
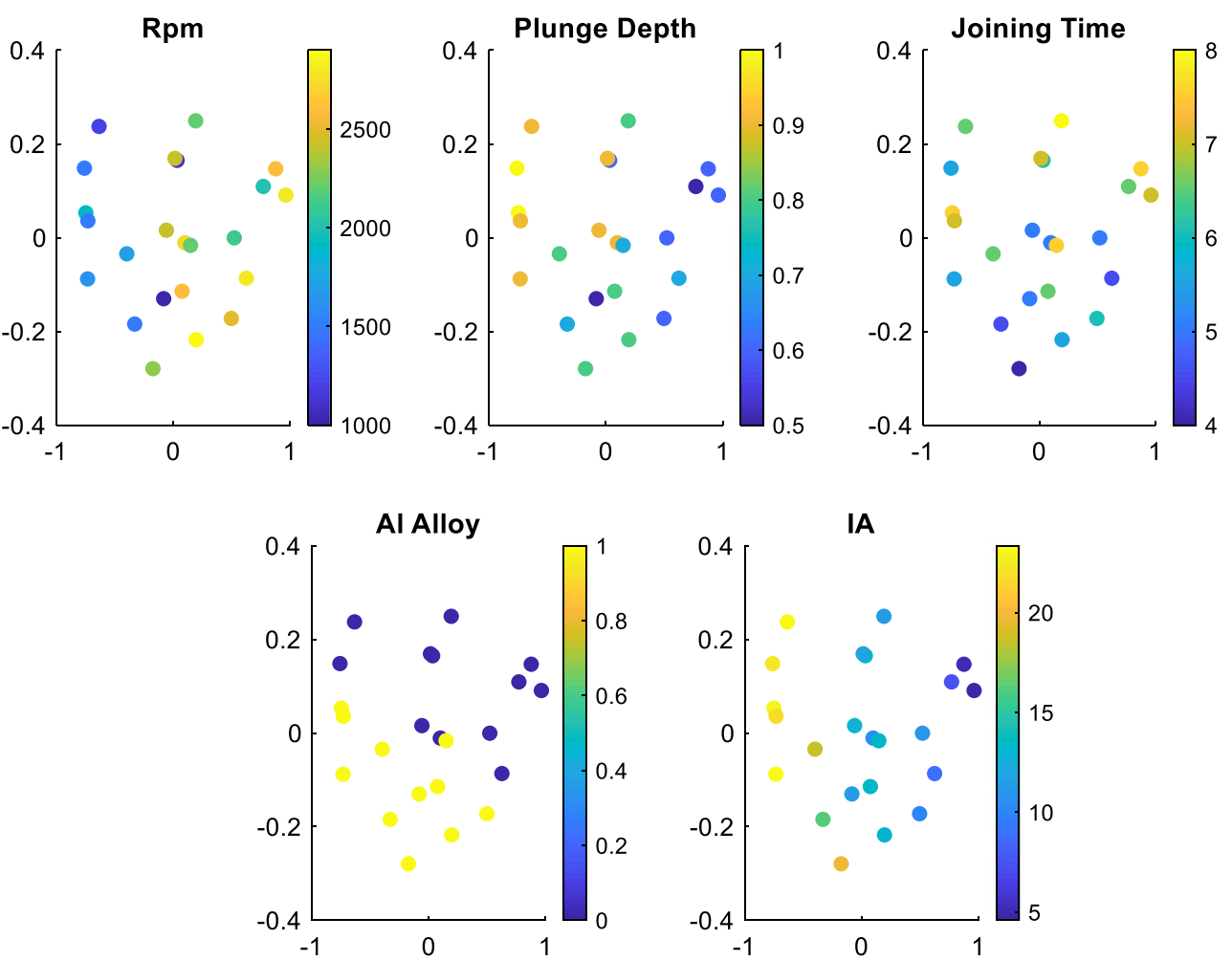

which highlights the classification of the heterogeneous data and aims at emphasizing the classification and nonlinear regression capabilities of this technique and, in conclusion, the compact equations obtained from the Newton-Raphson minimization technique.

\section{FE simulations results}

To assess the joint efficiency, the maximum temperature of the PC sheet in two specific zone close to the friction-heated aluminum side, and the interlocking area between the sheets were evaluated from all simulation results. These three outputs were chosen because they can be related to the degradation of the polymers at higher temperatures and to the strength of the connection.

Specifically, Fig. 5 illustrates the temperature distribution obtained with the 2D FE model, at the end of the phase "a"

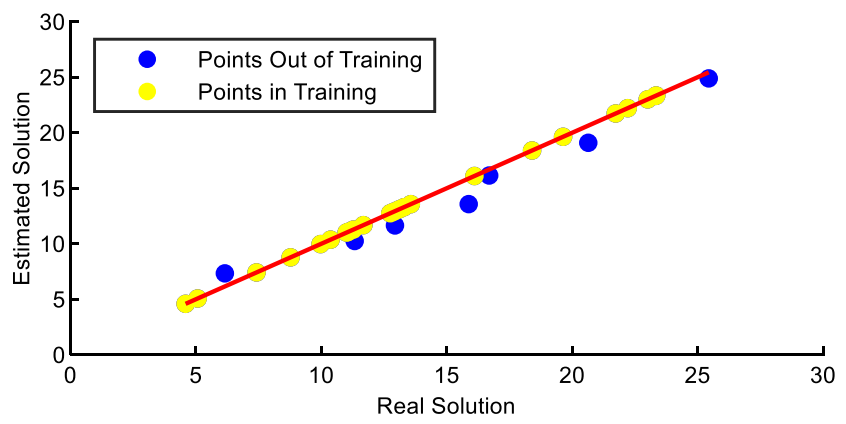

Fig. 12 Prediction of the IA and phase "b", as emphasized in Fig. 3. As expected, the maximum AA temperature is observable close to the rotating tool. Indeed, the metal reaches the melting temperature in the stir zone. Furthermore, analysing in depth the process dynamics, the melt zone is first gathered under the pin (Fig. 5a) and, subsequently, pushed to the plastic plate. A mechanical interlocking between the two plates (Fig. 5b) is, therefore, achieved.

Figure 6 illustrates the selected outputs, i.e. the maximum peak temperature (MPT) and the maximum valley temperature (MVT) on the PC sheet together with the interlocking area (IA) that is circumscribed with dashed lines.

Finally, Table 5 summarizes the calculated minimum and maximum values of the selected outputs.

\section{Code2Vect results: Vector space and regression}

In this section, the results of the Code2Vect application are presented, focusing on the classification of the heterogeneous

Table 6 Resulting coefficients of the eq. (5) for the AA 1050

\begin{tabular}{lrllr}
\hline Target/Input & ctt & a & b & \multicolumn{1}{c}{$c$} \\
\hline MTV & 1154 & $-0,097$ & 0,464 & 0,409 \\
MTP & 0,944 & $-0,051$ & 0,567 & 0,342 \\
IA & 5611 & $-0,155$ & 0,999 & $-0,170$ \\
\hline
\end{tabular}


Table 7 Resulting coefficients of the eq. (5) for the AA 2024

\begin{tabular}{lllll}
\hline $\begin{array}{l}\text { Target/ } \\
\text { Input }\end{array}$ & $\mathrm{ctt}$ & $\mathrm{a}$ & $\mathrm{b}$ & $\mathrm{c}$ \\
\hline MTV & 0,7275 & $-0,0373$ & 0,0075 & 0,3212 \\
MTP & 0,969 & $-0,013$ & 0,193 & 0,109 \\
IA & 15,470 & $-0,338$ & 1438 & 0,155 \\
\hline
\end{tabular}

data and on the classification and nonlinear regression capabilities of the adopted technique.

Specifically, from 4 dimensions, i.e., RS, PD, JT and AA, the space was reduced to 2 dimensions. Figure 7 depicts the vector space representation for the MTV. Each point represents one of the sample data, and it is colored at each time with the value of the input in the title. It is important to note that when applying Code2Vect the vector space involves the socalled reduced coordinates without specific units. By observing the colors, it can be seen how the AA equals to 0 , i.e., the AA 2024, is related to higher temperatures in the valley. Also, the RS value, labeled Rpm in Fig.7, is directly correlated to the temperature value because the tendency in the colors of the cluster for Rpm and MTV are similar. Finally, the joining time is also related to MTV even if the relationship seems to be less relevant than AA and Rpm while plunge depth results to have a marginal effect on this process output.

Figure 8 compares the MTV estimated solution taking into account in- and out-side training points. It can be seen how the predicted MTV values for the data outside the training (blue) is very accurate.

The same approach was used for the other two factors. Specifically, Fig. 9 shows the vector space representation for the MTP. The considerations, as reported for MTV, are valid for this output, which, therefore seems to be affected from the monitored process parameters, equally.

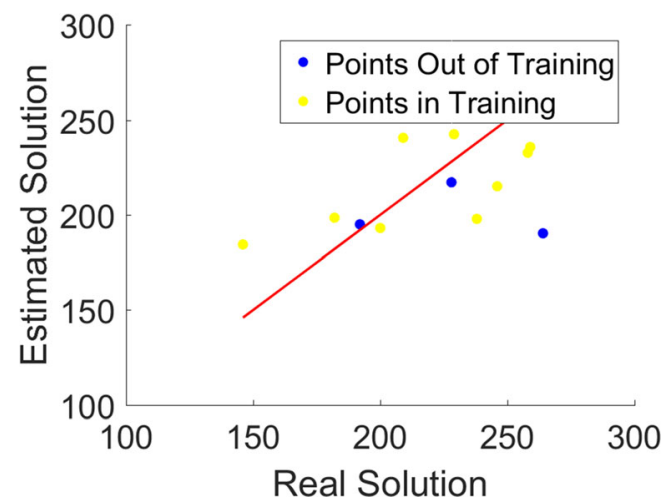

Fig. 13 Predicted value for the MTV of AA 1050: Estimated solution vs Real Solution

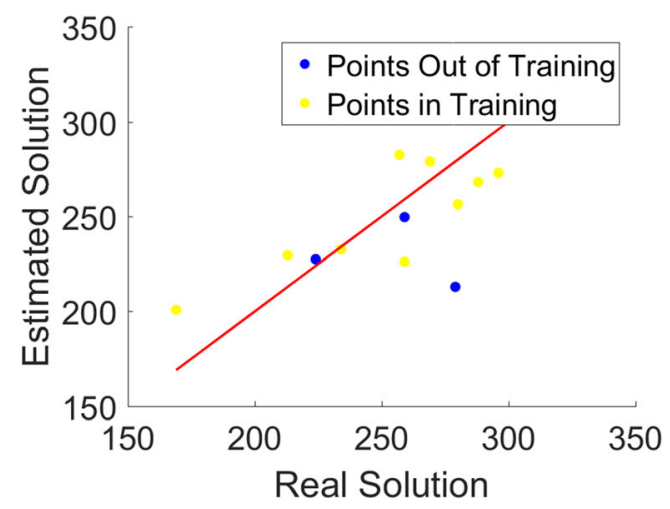

Fig. 14 Predicted value for the MTP of AA 1050: Estimated solution vs Real Solution

Figure 10 compares the MTP predicted values with those inside and outside the training. It can be seen how the predicted MTP values for the data outside the training (blue) is very accurate.

Concerning the IA, the vector space representation is illustrated in Fig. 11. By observing the colors, the evidences below reported can be derived:

- Rpm is inversely related to the IA;

- Plunge Depth is directly related to IA.

- Aluminum Alloy equals to 1, i.e., the AA 1050, characterized by softer mechanical properties, is the one with higher IA values.

- Joining time does not show a direct relationship to IA.

Finally, as reported in Fig. 12, it can be seen how the predicted IA values for the data outside the training (blue) is, once again, very accurate.

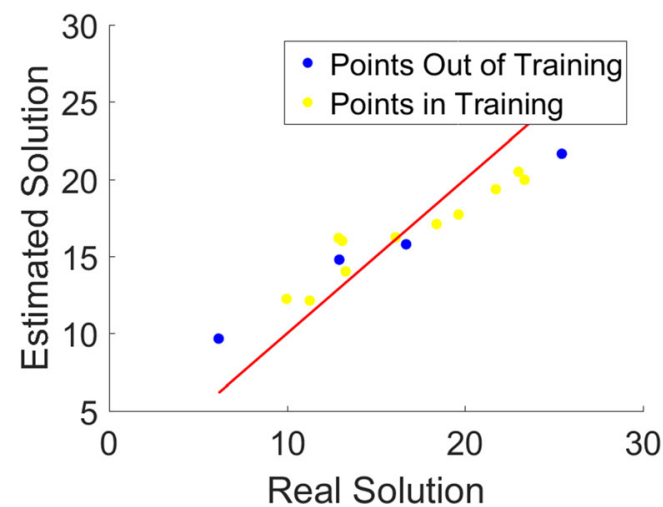

Fig. 15 Predicted value for the IA of AA 1050: Estimated solution vs Real Solution 


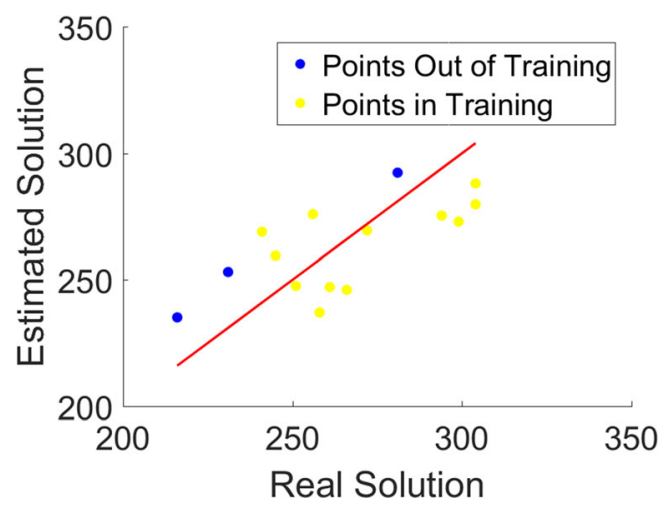

Fig. 16 Predicted value for the MTV of AA 2024: Estimated solution vs Real Solution

\section{Newton Raphson minimization towards a compact representation}

In this section, the results of the Newton-Raphson minimization is provided. Starting from Eq. 4, the calculated values for each quantity of interest (QoI) for each of the AA types can be written throughout the compact representation provided in the Eq. 5:

$Q o I_{\text {AA type }}=\mathrm{ctt} * R S^{\mathrm{a}} * P D^{b} * J T^{c}$

The four coefficients for the AA 1050 are reported in Table 6 , while the four coefficients for the AA 2024 are reported in Table 7.

Finally, Figs. 13-18 show, respectively, the predicted value for the points in the training and the points outside the training for the MTV, MTP, and IA for the AA 1050 and AA 2024.

In all the cases, predictions are promising. Specifically, lower errors are obtained if predictions are computed directly from the Code 2 Vect regression. However, the

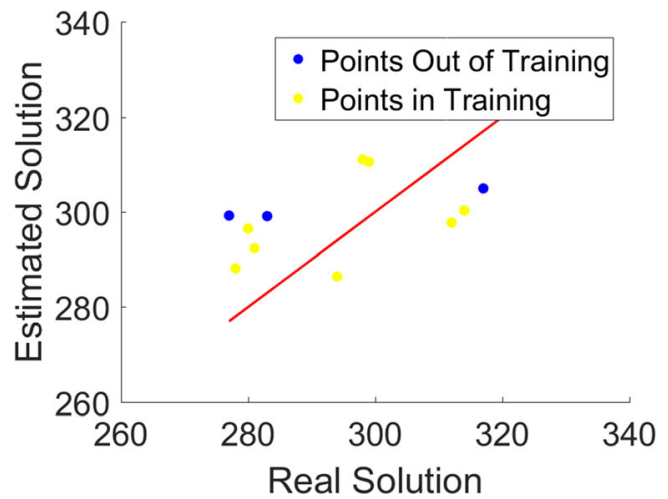

Fig. 17 Predicted value for the MTP of AA 2024: Estimated solution vs Real Solution

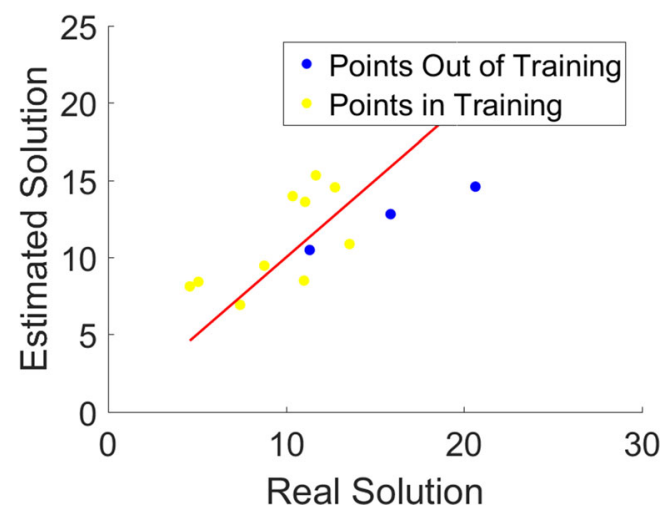

Fig. 18 Predicted value for the IA of AA 2024: Estimated solution vs Real Solution

single-term multiplicative compact expression (5) provides, as discussed, quite good predictions despite of its compactness and simplicity (low data employed).

\section{Conclusions}

In this work, the potential window for the Friction Spot Joining process was investigated in the case of joining dissimilar materials, i.e., aluminum alloys and polycarbonate. This research was carried out from a numerical point of view according to 2D FE simulations, planned according to a DoE, with the aid of a novel approach for sensitivity analysis.

Despite the 2D simplification neglects the material stirring around the pin, the proposed torsional model and strategy were able to provide important information on the performance of the process in the joint making.

Furthermore, the proposed approach enabled an efficient representation of the relevant parameters involved in the model nevertheless low-data available. Specifically, the Code2Vect algorithm allowed understanding the influence of each of the investigated process parameters on the monitored outputs. Finally, making use of the Newton Raphson Minimization technique, three equations able to predict the quantities of interest through a compact representation were derived for each of the investigated mayerials without considering the physics behind the process.

Funding Open access funding provided by Università della Calabria within the CRUI-CARE Agreement.

\section{Compliance with ethical standards}

Conflict of interest The authors declare that they have no conflict of interest. 


\section{Appendix}

Table 4 DoE matrix listing the 30 joining condition

\begin{tabular}{|c|c|c|c|c|}
\hline \multirow[t]{2}{*}{ Joining condition } & \multicolumn{4}{|l|}{ Factors } \\
\hline & RS (rpm) & $\mathrm{PD}(\mathrm{mm})$ & JT (s) & Material \\
\hline 1 & 2000 & 0.7 & 6 & AA 1050 \\
\hline 2 & 2800 & 0.7 & 4.5 & AA 2024 \\
\hline 3 & 1700 & 1 & 6 & AA 1050 \\
\hline 4 & 2100 & 0.6 & 5 & AA 2024 \\
\hline 5 & 1900 & 1 & 7.5 & AA 1050 \\
\hline 6 & 1400 & 0.6 & 8 & AA 2024 \\
\hline 7 & 2200 & 0.8 & 8 & AA 2024 \\
\hline 8 & 1500 & 0.9 & 7 & AA 1050 \\
\hline 9 & 1100 & 0.6 & 6 & AA 2024 \\
\hline 10 & 1000 & 0.5 & 5 & AA 1050 \\
\hline 11 & 2500 & 0.6 & 6 & AA 1050 \\
\hline 12 & 3000 & 0.5 & 7 & AA 1050 \\
\hline 13 & 2600 & 0.6 & 7.5 & AA 2024 \\
\hline 14 & 2600 & 0.8 & 6.5 & AA 1050 \\
\hline 15 & 1500 & 1 & 5.5 & AA 2024 \\
\hline 16 & 2400 & 0.9 & 5 & AA 2024 \\
\hline 17 & 2800 & 0.6 & 7 & AA 2024 \\
\hline 18 & 1600 & 0.9 & 5.5 & AA 1050 \\
\hline 19 & 1200 & 0.7 & 5 & AA 2024 \\
\hline 20 & 2300 & 0.8 & 4 & AA 1050 \\
\hline 21 & 1500 & 0.7 & 4.5 & AA 1050 \\
\hline 22 & 1200 & 0.9 & 6.5 & AA 2024 \\
\hline 23 & 1800 & 0.7 & 4.5 & AA 1050 \\
\hline 24 & 2700 & 0.9 & 5 & AA 2024 \\
\hline 25 & 2200 & 0.7 & 7.5 & AA 1050 \\
\hline 26 & 2400 & 0.9 & 7 & AA 2024 \\
\hline 27 & 1700 & 0.8 & 6.5 & AA 1050 \\
\hline 28 & 2900 & 0.8 & 5.5 & AA 1050 \\
\hline 29 & 1300 & 0.8 & 4 & AA 2024 \\
\hline 30 & 2000 & 0.5 & 6.5 & AA 2024 \\
\hline
\end{tabular}

Open Access This article is licensed under a Creative Commons Attribution 4.0 International License, which permits use, sharing, adaptation, distribution and reproduction in any medium or format, as long as you give appropriate credit to the original author(s) and the source, provide a link to the Creative Commons licence, and indicate if changes were made. The images or other third party material in this article are included in the article's Creative Commons licence, unless indicated otherwise in a credit line to the material. If material is not included in the article's Creative Commons licence and your intended use is not permitted by statutory regulation or exceeds the permitted use, you will need to obtain permission directly from the copyright holder. To view a copy of this licence, visit http://creativecommons.org/licenses/by/4.0/.

\section{References}

1. Kruse J, Jagodzinski A, Langner J, Stonis M, Behrens BA (2019) Investigation of the joining zone displacement of cross-wedge rolled serially arranged hybrid parts. Int J Mater Form 13(4). https://doi.org/10.1007/s12289-019-01494-3

2. Fang X, Kloska T (2019) Hybrid forming of sheet metals with long fiber-reinforced thermoplastics (LFT) by a combined deep drawing and compression molding process. Int J Mater Form 13(4). https:// doi.org/10.1007/s12289-019-01493-4

3. Goushegir SM, dos Santos JF, Amancio-Filho ST (2014) Friction spot joining of aluminum AA2024/carbon-fiber reinforced poly(phenylene sulfide) composite single lap joints: microstructure and mechanical performance. Mater Des 54:196-206. https://doi. org/10.1016/j.matdes.2013.08.034

4. Blaga L, Dos Santos JF, Bancila R, Amancio-Filho ST (2015) Friction riveting (FricRiveting) as a new joining technique in GFRP lightweight bridge construction. Constr Build Mater 80: 167-179. https://doi.org/10.1016/j.conbuildmat.2015.01.001

5. Amancio-Filho ST, dos Santos JF (2012) EP2329905B1 method for joining metal and plastic workpieces. European Patent

6. Schilling C, Dos Santos J (2001) Method and device for linking at least two adjoining work pieces by friction welding

7. D'Urso G, Giardini C (2016) FEM model for the thermomechanical characterization of friction stir spot welded joints. Int J Mater Form 9(2):149-160. https://doi.org/10.1007/s12289-015$1218-\mathrm{y}$

8. Goushegir SM, dos Santos JF, Amancio-Filho ST (2015) Influence of process parameters on mechanical performance and bonding area of AA2024/carbon-fiber-reinforced poly(phenylene sulfide) friction spot single lap joints. Mater Des 83:431-442. https://doi.org/ 10.1016/j.matdes.2015.06.044

9. Adibeig MR, Marami G, Saeimi-Sadigh MA, da Silva LFM (2020) Experimental and numerical study of polyethylene hybrid joints: friction stir spot welded joints reinforced with adhesive. Int $\mathrm{J}$ Adhes Adhes 98:102555. https://doi.org/10.1016/j.ijadhadh.2020. 102555

10. Yu M, Li WY, Li JL, Chao YJ (2012) Modelling of entire friction stir welding process by explicit finite element method. In: materials science and technology (United Kingdom). Pp 812-817

11. Malik V, Sanjeev NK, Hebbar HS, Kailas SV (2014) Investigations on the effect of various tool pin profiles in friction stir welding using finite element simulations. Procedia Engineering, In, pp 1060-1068

12. Ansari MA, Samanta A, Behnagh RA, Ding H (2019) An efficient coupled Eulerian-Lagrangian finite element model for friction stir processing. Int J Adv Manuf Technol 101(5-8):1495-1508. https:// doi.org/10.1007/s00170-018-3000-Z

13. Chen K, Liu X, Ni J (2019) A review of friction stir-based processes for joining dissimilar materials. Int J Adv Manuf Technol 104(58):1709-1731. https://doi.org/10.1007/s00170-019-03975-w

14. Chiumenti M, Cervera M, Agelet de Saracibar C, Dialami N (2013) Numerical modeling of friction stir welding processes. Comput Methods Appl Mech Eng 254:353-369. https://doi.org/10.1016/j. cma.2012.09.013

15. Argerich Martín C, Ibáñez Pinillo R, Barasinski A, Chinesta F (2019) Code2vect: an efficient heterogenous data classifier and nonlinear regression technique. Comptes Rendus - Mec 347(11): 754-761. https://doi.org/10.1016/j.crme.2019.11.002

16. Lang L, Cai G, Liu K, Alexandrov S, du P, Zheng H (2015) Investigation on the effect of through thickness normal stress on forming limit at elevated temperature by using modified M-K model. Int J Mater Form 8(2):211-228. https://doi.org/10.1007/s12289014-1161-3 
17. Buffa G, Hua J, Shivpuri R, Fratini L (2006) A continuum based fem model for friction stir welding - model development. Mater Sci Eng A 419(1-2). https://doi.org/10.1016/j.msea.2005.09.040

18. Fuller JJ, Marotta EE (2001) Thermal contact conductance of metal/ polymer joints: an analytical and experimental investigation. $\mathrm{J}$ Thermophys Heat Transf 15(2):228-238. https://doi.org/10.2514/ 2.6598

19. Johnson GR, Cook WH (1983) A constitutive model and data from metals subjected to large strains, high strain rates and high temperatures. In: Proc. 7 th $\{\mathrm{I}\}$ nt. $\{\mathrm{S}\}$ ymp. On $\{\mathrm{B}\}$ allistics, $\{\mathrm{T}\}$ he $\{\mathrm{H}\}$ ague, $\{\mathrm{N}\}$ etherlands

20. Eide HOS, Melby EA (2013) Blast loaded aluminium plates experiments and numerical simulations. 1-139

21. Asad M, Girardin F, Mabrouki T, Rigal JF (2008) Dry cutting study of an aluminium alloy (A2024-T351): a numerical and experimental approach. Int J Mater Form 1(S1). https://doi.org/10.1007/ s12289-008-0150-9
22. Duan Y, Saigal A, Greif R, Zimmerman MA (2001) A uniform phenomenological constitutive model for glassy and semicrystalline polymers. Polym Eng Sci 41(8):1322-1328. https://doi.org/10. 1002/pen.10832

23. Neuhauser FM, Bachmann G, Hora P (2019) Surface defect classification and detection on extruded aluminum profiles using convolutional neural networks. Int J Mater Form 13(4). https:// doi.org/10.1007/s12289-019-01496-1

24. Ibáñez R, Abisset-Chavanne E, González D, Duval JL, Cueto E, Chinesta F (2019) Hybrid constitutive modeling: data-driven learning of corrections to plasticity models. Int J Mater Form 12(4):717725. https://doi.org/10.1007/s12289-018-1448-x

Publisher's note Springer Nature remains neutral with regard to jurisdictional claims in published maps and institutional affiliations. 